\title{
GADD45 $\beta$ induction by S-adenosylmethionine inhibits hepatocellular carcinoma cell proliferation during acute ischemia-hypoxia
}

\author{
Ding Ma ${ }^{1, *}$, Baiyong Shen ${ }^{1, *}$, Varun Seewoo ${ }^{1, *}$, Hui Tong ${ }^{2}$, Weiping Yang ${ }^{1}$, Xi Cheng ${ }^{1}$, \\ Zhijian Jin ${ }^{1}$, Chenghong Peng ${ }^{1}$, Weihua Qiu ${ }^{1}$ \\ ${ }^{1}$ Department of Surgery, Ruijin Hospital, Shanghai Jiao Tong University School of Medicine, Shanghai, China \\ ${ }^{2}$ Department of Surgery, Huadong Hospital, Shanghai, China \\ *These authors have contributed equally to this work \\ Correspondence to: Weihua Qiu, e-mail: drqwh2003@yahoo.com \\ Chenghong Peng, e-mail: qwh11072@rjh.com.cn
}

Keywords: hepatocellular carcinoma, S-adenosylmethionine, ischemia-hypoxia, GADD45 3 , apoptosis

Received: March 02, $2016 \quad$ Accepted: April 26, 2016

Published: May 11, 2016

\section{ABSTRACT}

Growth arrest DNA damage-inducible gene $45 \beta$ (GADD45 $\beta$ ), which influences cell growth, apoptosis and cellular response to DNA damage, is downregulated in hepatocellular carcinoma (HCC). S-adenosylmethionine (SAMe) serves as an essential methyl donor in multiple metabolic pathways and is a polyamine and glutathione (GSH) precursor. In this study, we assessed the roles of GADD45 $\beta$ and SAMe in cell survival during acute ischemia-hypoxia (I/H). SAMe treatment induced growth of HL-7702 normal hepatic cells, but decreased the viability of HepG2 (p53 wild-type) and Hep3B (p53 nulI) HCC cells. Cells were exposed to I/H with or without SAMe pre-treatment. I/H exposure alone triggered HCC cell proliferation promoted by autophagy. SAMe pre-treatment restored GADD45 $\beta$ expression and activated HCC cell apoptosis and eliminated I/H-induced HCC cell proliferation. p53 loss blunted the response to SAMe and I/H exposure in Hep3B cells; thus, the inhibitory effect of SAMe on cell proliferation may be reduced in p53-null cells as compared to wild-type cells. These results indicate that GADD45 $\beta$ induction by SAMe inhibits HCC cell proliferation during $\mathrm{I} / \mathrm{H}$ as a result of increased apoptosis, and that SAMe also protects normal hepatocytes from apoptotic cell death and promotes normal cell regeneration. SAMe should be considered a potential therapeutic agent for the management of HCC.

\section{INTRODUCTION}

Despite recent progress in diagnostic and therapeutic management, hepatocellular carcinoma (HCC) patient prognosis remains poor [1-4]. The level of downregulation of growth arrest DNA damage-inducible gene $45 \beta$ (GADD45b) in HCC is strongly correlated with increased tumor malignancy [5]. GADD $45 \beta$ is associated with cell growth control, apoptosis and cellular responses to DNA damage [6]. Consequently, lack of GADD $45 \beta$ expression in HCC might lead to atypical cell growth or apoptosis. Therefore, GADD45b has been identified as a potential molecular marker and therapeutic target in both $\mathrm{HCC}$ and chronic liver diseases.

A characteristic of locally advanced solid tumors like $\mathrm{HCC}$ is tumor hypoxia, resulting from an imbalance in oxygen supply and consumption [7]. Our previous study showed that acute ischemia-hypoxia $(\mathrm{I} / \mathrm{H})$ exposure may trigger compensatory $\mathrm{HCC}$ cell proliferation, and that autophagy plays an important role in HCC cell survival during acute $\mathrm{I} / \mathrm{H}[8,9]$.

S-adenosylmethionine (SAMe) is an essential compound in many metabolic pathways, serving as a methyl donor and a precursor for polyamines and glutathione (GSH) [10]. Most patients with liver injury or a chronic liver disease, like cirrhosis, have impaired SAMe biosynthesis due to reduced MAT1A expression and MAT I/III inactivation, which are respectively the enzyme and isoenzyme involved in SAMe synthesis in normal hepatocytes $[11,12]$. SAMe may inhibit tumor growth, reduce tumor invasiveness and slow metastasis through methyl group donation leading to gene hypermethylation 
and reduction of overall hypomethylation to inhibit oncogene expression [13-15].

In the present study, the effect of SAMe on cultured HepG2 (p53-wild type), Hep3B (p53-null) hepatoma cells and HL-7702 normal hepatic cells was investigated. On establishment of an acute $\mathrm{I} / \mathrm{H}$ model in vitro, the impact of SAMe pre-treatment during I/H was studied, and the potential role of $p 53$ in the model was explored.

\section{RESULTS}

\section{Effects of SAMe on cell viability}

The effects of SAMe on HCC and normal liver cell viability were examined. Exposure to low SAMe concentrations $(0-10 \mathrm{mmol} / \mathrm{L})$ for $24 \mathrm{~h}$ significantly induced HL-7702 cell growth. At the optimal concentration of $5 \mathrm{mmol} / \mathrm{L}$, cell proliferation was enhanced by about 52\% (152.09 $\pm 4.78 \%)$. However, higher SAMe concentrations (10-20 mmol/L) and longer exposure times (48 or 72 h) inhibited HL-7702 growth. Meanwhile, SAMe treatment resulted in dose and time dependent inhibition of HepG2 and Hep3B cell proliferation. With $5 \mathrm{mmol} / \mathrm{L}$ SAMe for $24 \mathrm{~h}$, HepG2 cell viability was reduced by about $29.2 \%(70.8 \pm 4.5 \%)$ and that of Hep3B by about $13.0 \%$ $(87.1 \pm 2.8 \%)$. At SAMe concentrations that inhibited HL7702 cell growth, cell viability was still higher than that of HepG2 and Hep3B. Therefore, in subsequent experiments cells were exposed to $5 \mathrm{mmol} / \mathrm{L} \mathrm{SAMe}$ for $24 \mathrm{~h}$; this concentration had the maximal pro-proliferation effect on HL-7702 cells, while the two hepatoma cell lines were adequately inhibited (Figure 1).

\section{Effects of acute I/H on cell proliferation with/ without SAMe pre-treatment}

To explore the influence of SAMe on HCC during $\mathrm{I} / \mathrm{H}$, we established an $\mathrm{I} / \mathrm{H}$ model as per our previous study [9]. Cell proliferation rates were examined across the different groups. I/H increased HepG2 proliferation by $33.2 \pm 7.8 \%(p<0.05)$ (Figure 2$)$. Meanwhile, SAMe inhibited HepG2 cell growth by about $30.6 \pm 4.2 \%$ $(p<0.05)$. The SAMe inhibitory effect was further enhanced when pre-treated HepG2 cells were exposed to $\mathrm{I} / \mathrm{H}$. Cell viability of group $\mathrm{S}-\mathrm{I} / \mathrm{H}$ was only $31.6 \pm 1.6 \%$ (group I/H: $133.4 \pm 7.8 \%$ vs. group $\mathrm{S}-\mathrm{I} / \mathrm{H}: 31.6 \pm 1.6 \%$, $p<0.05)$.

A comparable effect was observed in Hep3B cells. Cell viability was slightly reduced by $13.2 \pm 3.6 \%$ after SAMe treatment (group S: $85.6 \pm 3.6 \%$ vs. group C: $98.8 \pm 3.7 \%, p>0.05)$, but after $\mathrm{I} / \mathrm{H}$ exposure, cell viability increased by $20.1 \pm 5.2 \%$. The SAMe inhibitory effect was again enhanced when pre-treated cells were exposed to $\mathrm{I} / \mathrm{H}$, with a resulting cell viability of $71.2 \pm 3.8 \%$ (group I/H: $119.9 \pm 5.2 \%$ vs. group S-I/H: $71.2 \pm 3.8 \%, p<0.05$ ).

HL-7702 cell proliferation was markedly induced $31.0 \pm 3.2 \%$ by SAMe, while ischemia and $\mathrm{I} / \mathrm{H}$ led to $16.4 \pm 2.2 \%$ and $20.3 \pm 3.4 \%$ decreases in cell viability, respectively. A $17.2 \pm 2.9 \%$ proliferation increase was measured with SAMe pre-treatment by followed by $\mathrm{I} / \mathrm{H}$.

We further explored the effects of acute $\mathrm{I} / \mathrm{H}$ on HCC cells with different $p 53$ contexts ( $p 53$ wild-type and null). To eliminate differences in growth characteristics between HepG2 and Hep3B cells, proliferation rates were compared according to SAMe pre-treatment and/

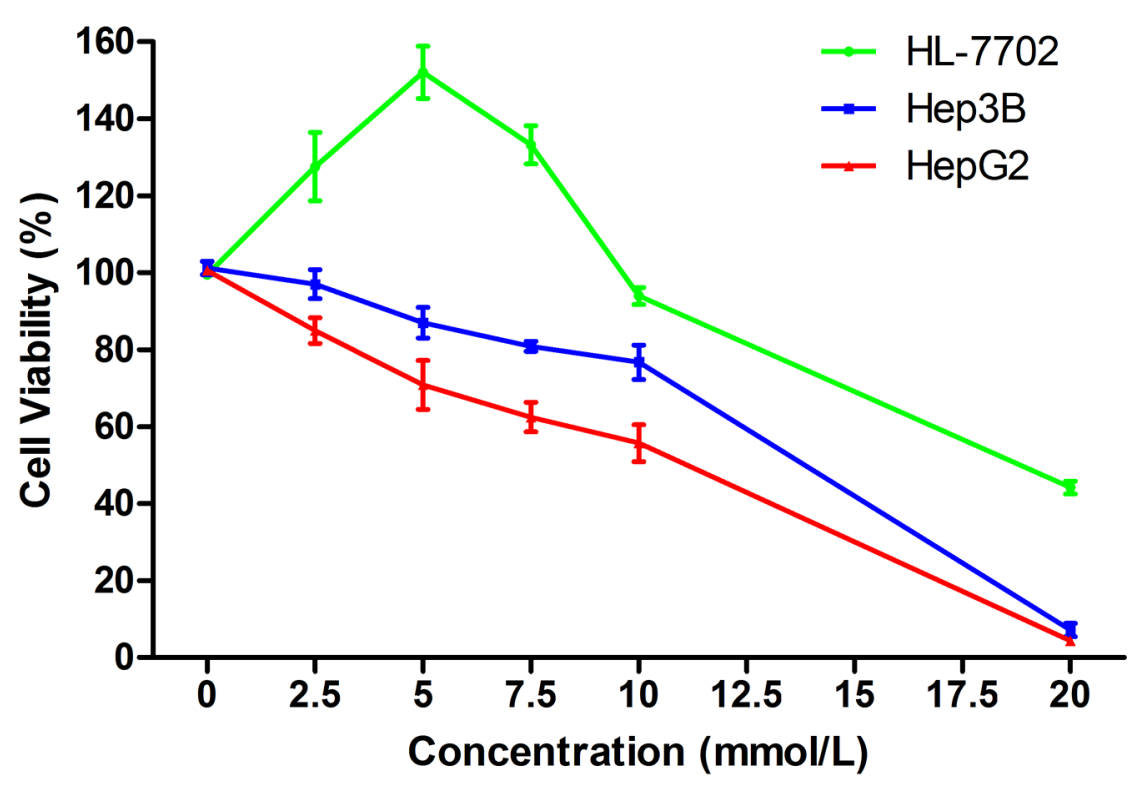

Figure 1: Effects of SAMe on cell viability. Treatment with low SAMe concentrations (0-10 mmol/L) for $24 \mathrm{~h}$ induced HL-7702 cell growth, with an optimal increase in viability at $5 \mathrm{mmol} / \mathrm{L}$. Higher concentrations $(10-20 \mathrm{mmol} / \mathrm{L})$ inhibited HL-7702 cell growth. SAMe treatment resulted in a dose-dependent inhibition of HepG2 and Hep3B cell proliferation. 
or $\mathrm{I} / \mathrm{H}$ exposure. The SAMe inhibitory effect on Hep3B cell proliferation was reduced compared to HepG2 cells (13.2 $\pm 3.6 \%$ vs. $30.6 \pm 4.2 \%, p<0.05)$ (Figure 2). Exposure to acute $\mathrm{I} / \mathrm{H}$ induced HepG2 and Hep3B cell proliferation with no significant difference between the two lines $(33.2 \pm 7.8 \%$ vs. $21.1 \pm 5.2 \%, p>0.05)$. When SAMe pretreatment was followed by $\mathrm{I} / \mathrm{H}$ exposure, Hep3B cell proliferation was increased as compared to HepG2 cells (71.2 $\pm 3.8 \%$ vs. $31.6 \pm 1.6 \%, p<0.01)$. Furthermore, HepG2 cell proliferation was increased by SAMe pre-treatment alone as compared to pre-treatment followed by $\mathrm{I} / \mathrm{H}$ (69.6 $\pm 4.2 \%$ vs. $31.6 \pm 1.6 \%, p<0.01)$; this difference was not observed in Hep3B cells $(85.6 \pm 3.6 \%$ vs. $71.2 \pm 3.8 \%$, $p>0.05)$.

These results showed that $\mathrm{I} / \mathrm{H}$ increased $\mathrm{HCC}$ cell viability. In addition to inhibiting $\mathrm{HCC}$ cell proliferation alone, SAMe pre-treatment reversed $\mathrm{I} / \mathrm{H}$-induced cell proliferation. Contrary growth patterns were observed in human normal hepatocyte HL-7702 cells; I/H reduced proliferation while SAMe promoted it. Pre-treatment with SAMe allowed normal hepatocytes to survive $\mathrm{I} / \mathrm{H}$. Consistent with our previous study [9], p53 might play an important role in the effect of SAMe on HCC cells.

\section{Acidic vesicular organelles (AVOs) in cells during I/H, with/without SAMe pre-treatment}

Our previous study showed that acute $\mathrm{I} / \mathrm{H}$ exposure may trigger compensatory HCC cell proliferation, and that autophagy plays an important role in $\mathrm{HCC}$ cell survival during acute $\mathrm{I} / \mathrm{H}$ [9]. Autophagy is characterized by AVO formation, and acridine orange staining was used to morphologically detect AVOs. Typical acridine orange accumulation in acidic AVOs appears as granular bright red fluorescence in the cytoplasm, indicating autophagosome formation. Acridine orange staining of live HepG2 and Hep3B cells showed increased AVO formation following SAMe pre-treatment (Figure 3A). Consistent with our previous results [4], I/H exposure increased AVOs amount in both HepG2 and Hep3B cells. Acute I/H with SAMe pre-treatment had no apparent influence on AVO formation in Hep3B cells, while a notable increase in AVOs was observed in HepG2 cells. AVO accumulation in HL-7702 cell cytoplasm was not changed by SAMe and/ or $\mathrm{I} / \mathrm{H}$ treatment.

The red-to-green fluorescence ratio (AVO accumulation) increased compared to controls in both HepG2 and Hep3B cells after $\mathrm{I} / \mathrm{H}$ exposure (HepG2: $0.70 \pm 0.04$ vs. $0.42 \pm 0.03, p<0.05$; Hep3B: $0.69 \pm 0.03$ vs. $0.43 \pm 0.04, p<0.05$ ) (Figure $3 \mathrm{~B}$ ). Additionally, the redto-green fluorescence ratio increased in SAMe-treated HepG2 and Hep3B cells (group S) compared to controls (HepG2: $0.90 \pm 0.07$ vs. 0.42 $\pm 0.03, p<0.05$; Нер3B: $0.71 \pm 0.04$ vs. $0.43 \pm 0.04, p<0.05)$, suggesting that SAMe treatment could induce autophagy. When HepG2 cells were pre-treated with $\mathrm{SAMe}$ and then exposed to $\mathrm{I} / \mathrm{H}$ (group $\mathrm{S}-\mathrm{I} / \mathrm{H}$ ), AVO formation increased significantly (groups S-I/H vs. I/H: $0.95 \pm 0.03$ vs. $0.70 \pm 0.04, p<0.05$ ). SAMe pre-treatment failed to enhance $\mathrm{I} / \mathrm{H}$ exposureinduced autophagy in Hep3B cells (groups $\mathrm{S}-\mathrm{IH}$ vs. I/H:

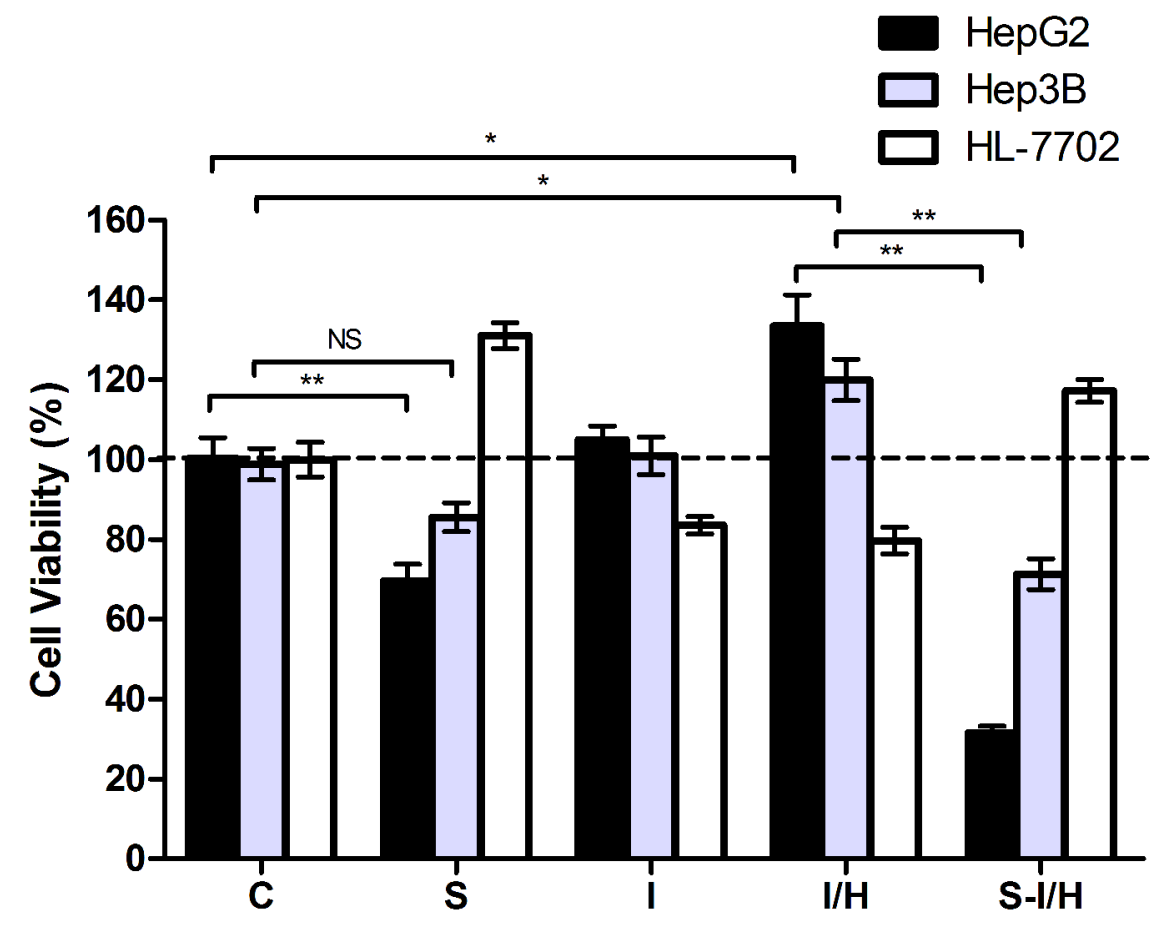

Figure 2: Effects of acute $\mathbf{I} / \mathbf{H}$ on cell proliferation with/without SAMe pre-treatment. Comparison of cell proliferation among Control (C), SAMe treatment (S), Ischemia (I), Ischemia-Hypoxia (I/H) and SAMe pre-treatment (S-I/H) groups. NS $p>0.05$; $* p<0.05 ; * * p<0.01$ 
$0.74 \pm 0.05$ vs. $0.69 \pm 0.03, p>0.05)$. While a mild increase in autophagosome formation was observed in HL-7702 cell $\mathrm{I} / \mathrm{H}$ and $\mathrm{S}$ groups, no changes were statistically significant.

These data showed that SAMe and/or acute $\mathrm{I} / \mathrm{H}$ exposure induced autophagy in HepG2 and Hep3B cells, but not HL-7702 cells. SAMe pre-treatment triggered autophagy only in HepG2 cells.

\section{Beclin 1 expression during $\mathrm{I} / \mathrm{H}$, with/without SAMe pre-treatment}

Beclin $1 \mathrm{mRNA}$ levels were evaluated to confirm autophagy activation following SAMe and/or acute $\mathrm{I} / \mathrm{H}$ exposure [16]. Beclin 1 expression was increased in SAMe-treated HepG2 cells (group C: $13.4 \pm 1.2$ vs. group S: $37.2 \pm 1.8, p<0.01$ ) (Figure 4A). Only a minimal increase in autophagy was observed with ischemia (group I: $15.8 \pm 1.0 v s$. group C: $13.4 \pm 1.2, p>0.05)$. In contrast, $\mathrm{I} / \mathrm{H}$ induced autophagy in HepG2 cells, and Beclin 1 levels increased from $13.4 \pm 1.2$ in group $C$ to $21.9 \pm 0.7$ in group I/H $(p<0.05)$. When HepG2 cells were treated with SAMe prior to $\mathrm{I} / \mathrm{H}$ (group $\mathrm{S}-\mathrm{I} / \mathrm{H}$ ), there was little change in Beclin 1 expression compared with group $\mathrm{S}$, but there was a significant increase as compared with group $\mathrm{I} / \mathrm{H}(\mathrm{S}-\mathrm{I} / \mathrm{H}$ : $34.7 \pm 1.6$ vs. S: $37.2 \pm 1.8, p>0.05$; S-I/H: $34.7 \pm 1.6$ vs. I/H: $21.9 \pm 0.7, p<0.01)$.

Similar autophagic activity changes occurred in Hep3B cells (Figure 4B). After SAMe treatment, Beclin 1 expression increased from $3.4 \pm 0.4$ in controls to $14.1 \pm 0.8$ in group $\mathrm{S}(p<0.01)$. Ischemia alone (group I) barely induced autophagy and Beclin 1 levels were unchanged (3.7 \pm 0.6 vs. $3.4 \pm 0.4$ in controls, $p>0.05$ ). However, $\mathrm{I} / \mathrm{H}$ triggered a Beclin 1 expression increase to $9.7 \pm 0.6$ (group
$\mathrm{I} / \mathrm{H}, p<0.05)$. Pre-treatment with SAMe did not further enhance Beclin 1 levels (group $\mathrm{I} / \mathrm{H}: 9.7 \pm 0.6$ vs. group $\mathrm{S}-\mathrm{I} / \mathrm{H}: 10.7 \pm 0.8, p>0.05)$.

Similar to the results of the AVO formation assay, Beclin 1 expression in HL-7702 cells was unchanged by the treatments. Beclin 1 levels marginally increased with SAMe treatment, decreased after $\mathrm{I} / \mathrm{H}$ and were slightly restored by SAMe pre-treatment before $\mathrm{I} / \mathrm{H}(\mathrm{C}$ : $20.2 \pm 0.8, \mathrm{~S}: 25.5 \pm 1.7, \mathrm{I} / \mathrm{H}: 18.0 \pm 1.0, \mathrm{~S}-\mathrm{I} / \mathrm{H}: 22.6 \pm 1.8$; groups $\mathrm{C} v s . \mathrm{S}, p>0.05$; groups $\mathrm{C} v s . \mathrm{I} / \mathrm{H}, p>0.05$; groups $\mathrm{S} v s$. S-I/H, $p>0.05$; groups $\mathrm{I} / \mathrm{H}$ vs. $\mathrm{S}-\mathrm{I} / \mathrm{H}, p>0.05$ ) (Figure $4 \mathrm{C})$. Steady state Beclin1 levels in hepatoma cell lines HepG2 and Hep3B were significantly lower than that in normal hepatocyte HL-7702 cells, with levels in HepG2 lower than those in Hep3B cells. Beclin 1 expression in HepG2, Hep3B and HL-7702 cells was $13.4 \pm 1.2,3.4 \pm 0.4$ and 20.2 \pm 0.8 , respectively (HepG2 vs. HL-7702, $p<0.05$; Hep3B vs. HL-7702, $p<0.01)$.

Consistent with our previous study [9], I/H and SAMe treatment both induced autophagy in HCC cells. Furthermore, Beclin 1 expression differences between the two HCC cell lines suggested that p53 might play a role in autophagy regulation in response to $\mathrm{I} / \mathrm{H}$ after SAMe pretreatment.

\section{Effects of autophagy on HCC cell proliferation during acute $\mathbf{I} / \mathbf{H}$, with/without SAMe pre- treatment}

An essential autophagy gene, ATG7 is an E1-like enzyme involved in MAP-LC3 ubiquitination early in the pathway, and ATG7 knockdown inhibits autophagy specifically [17]. HCC cells were transfected with ATG7

B

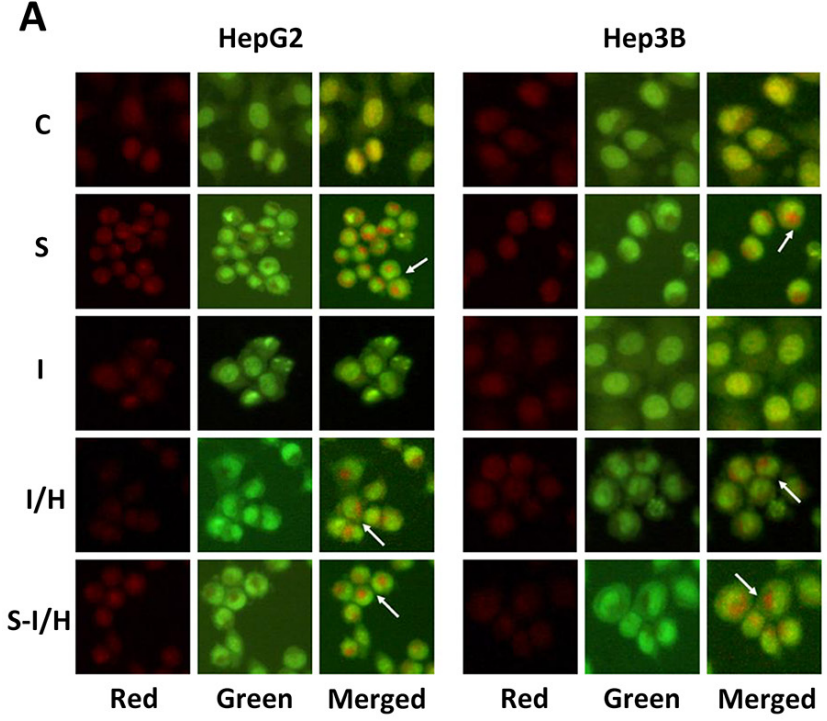

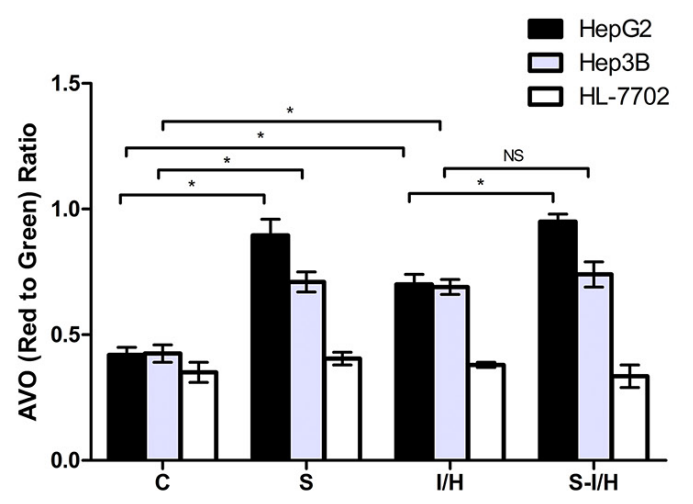

Figure 3: AVOs in cells during I/H, with/without SAMe pre-treatment. Qualitative AVO analyses A. Staining of live HepG2 and Hep3B cells for AVOs revealed the formation of LC3 puncta. Quantitative AVO analyses B. AVOs were quantitatively assessed according to the red-to-green fluorescence ratio obtained using Photoshop software. NS $p>0.05 ; * p<0.05$. 
small interfering RNAs (siRNAs) to assess the effects of autophagy during acute $\mathrm{I} / \mathrm{H}$ with or without SAMe pretreatment.

ATG7 interference inhibited Beclin 1 increases induced by $\mathrm{I} / \mathrm{H}$ treatment in both HepG2 and Hep3B cells
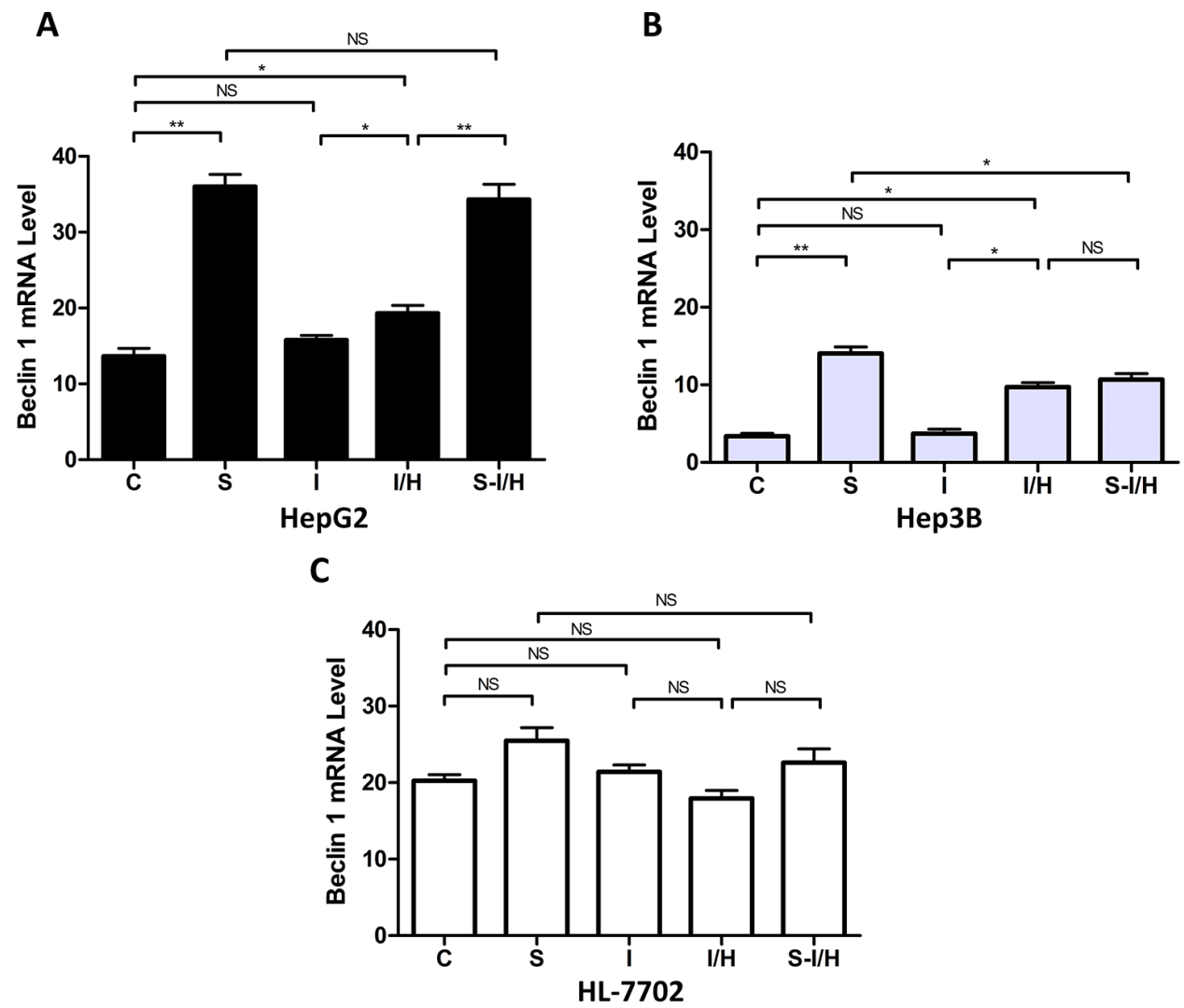

Figure 4: Beclin 1 expression during I/H, with/without SAMe pre-treatment. Beclin 1 levels in HepG2 (p53 wild type) A. Hep3B ( $p 53$ null) B. and HL-7702 (normal liver) C. cells in all treatment groups. NS $p>0.05 ; * p<0.05 ; * * p<0.01$.

A

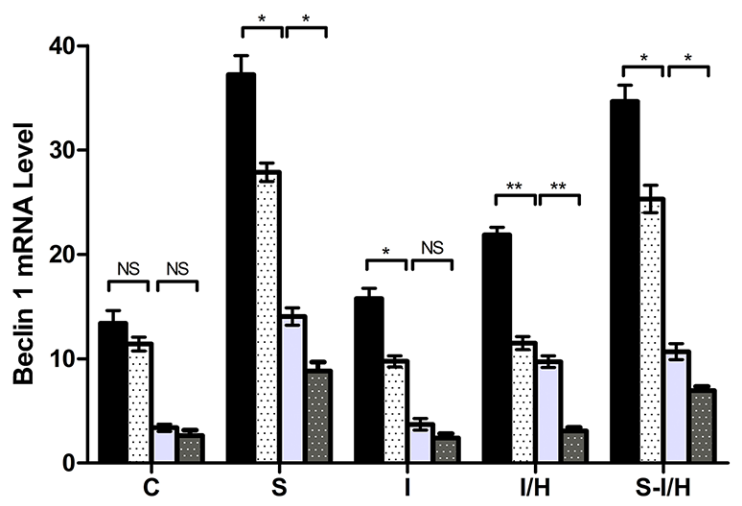

(Figure 5A). Beclin 1 levels in HepG2 and Hep3B cells decreased approximately $47.4 \%$ and $68.4 \%$, respectively, during I/H following ATG7 knockdown (group I/H-si vs. I/H, HepG2: $11.5 \pm 0.6$ vs. 21.9 \pm 0.7 , Hep3B: $3.1 \pm 0.3$ vs. $9.7 \pm 0.6, p<0.01)$. A comparable effect was observed in 
group S-si as well. ATG7 knockdown inhibited SAMeinduced Beclin 1 expression in HepG2 and Hep3B cells. Beclin 1 levels decreased from $37.2 \pm 1.8$ to $27.9 \pm 0.9$ in HepG2 $(p<0.05)$ and from $14.1 \pm 0.8$ to $8.8 \pm 0.9$ in Hep3B cells $(p<0.05)$. Similar to our previous results, ATG7 knockdown inhibited Beclin 1 expression in HepG2 and Hep3B cells in group S-I/H-si compared with group S-I/H (HepG2: $25.3 \pm 1.3$ vs. $34.7 \pm 1.6, p<0.05$, Hep3B: $6.9 \pm 0.4$ vs. $10.7 \pm 0.8, p<0.05)$. These results showed that ATG7 knockdown inhibited autophagy in almost all treatment groups.

ATG7 knockdown alone had almost no inhibitory effect on HepG2 and Hep3B cell proliferation (group C vs. C-si, HepG2: $100.3 \pm 5.2 \%$ vs. $105.0 \pm 2.3 \%, p>0.05$; Hep3B: $98.1 \pm 4.6 \%$ vs. $103.8 \pm 2.9 \%, p>0.05$ ) (Figure $5 \mathrm{~B}$ ). AtG7 knockdown inhibited $\mathrm{I} / \mathrm{H}$-induced proliferation in HepG2 and Hep3B cells approximately $46.8 \%$ and $40.3 \%$, respectively (group I/H vs. I/H-si, HepG2: 133.4 $\pm 7.8 \%$ vs. $71.0 \pm 5.6 \%$, Hep3B: $119.9 \pm 5.2 \%$ vs. $71.6 \pm 6.7 \%, p<0.01)$. Meanwhile, ATG7 knockdown only minimally influenced proliferation in groups S-si and S-I/H-si in both HepG2 and Hep3B cells (group S vs. S-si, HepG2: 69.6 $44.2 \%$ vs. $68.1 \pm 3.3 \%$, Нep3B: $85.6 \pm 3.6 \%$ vs. $82.6 \pm 4.5 \%$, $p>0.05$; group S-I/H vs. S-I/H-si, HepG2: $31.6 \pm 1.6 \%$ vs. $26.4 \pm 4.4 \%$, Hep3B: $71.2 \pm 3.8 \%$ vs. $70.0 \pm 6.2 \%, p>0.05$ ).

These results collectively suggested that the observed inhibitory effect of ATG7 knockdown on HCC cell proliferation following acute $\mathrm{I} / \mathrm{H}$ exposure most likely resulted from ATG7 knockdown-induced autophagy inhibition. Importantly, ATG7 knockdown did not influence HCC cell proliferation during acute $\mathrm{I} / \mathrm{H}$ with $\mathrm{SAMe}$ pre-treatment. These results indicated that in addition to autophagy, other mechanisms may be involved in elimination of $\mathrm{I} / \mathrm{H}$-induced HCC cell proliferation by SAMe pre-treatment.

\section{Apoptotic response of $\mathrm{HCC}$ cells during acute I/H with/without SAMe}

We performed flow cytometry to assess the apoptotic response of HCC cells to SAMe treatment. The percentage of apoptotic cells following $\mathrm{I} / \mathrm{H}$ exposure increased from $8.5 \pm 0.6 \%$ to $23.4 \pm 1.4 \%(p<0.01)$ in HepG2 and from $8.2 \pm 1.7 \%$ to $18.4 \pm 1.3 \%(p<0.05)$ in Hep3B cells (Figure 6). When first pre-treated with SAMe and then exposed to $\mathrm{I} / \mathrm{H}$, the total fraction of apoptotic HepG2 cells increased to $64.9 \pm 3.4 \%(p<0.01)$; no change was observed in Hep3B cells $(23.5 \pm 2.1 \%, p>0.05)$. The apoptotic effect mostly resulted from an increased percentage of cells in late apoptosis $\left(\right.$ Annexin $\left.\mathrm{V}^{+} / \mathrm{PI}^{+}\right)$. Therefore, the inhibitory effect of SAMe on $\mathrm{I} / \mathrm{H}$-induced HCC cell proliferation was accomplished via activation of the apoptotic pathway.

\section{Influence of I/H on GADD45 $\beta$ expression with/ without SAMe pre-treatment}

Our previous study showed that SAMe induced GADD $45 \beta$ via NF- $\kappa$ B [18] and NF- $\kappa$ B played an important role in cell apoptosis. Here, the influence of $\mathrm{I} / \mathrm{H}$ on GADD $45 \beta$ expression with and without SAMe was examined. When HepG2 cells were exposed to $5 \mathrm{mmol} / \mathrm{L}$ SAMe for $24 \mathrm{~h}$, GADD45 $\beta$ expression was $14.8 \pm 0.9$ compared with $6.0 \pm 0.4$ in the control group $(p<0.01)$ (Figure 7A). Moreover, both ischemia and $\mathrm{I} / \mathrm{H}$ inhibited GADD $45 \beta$ expression (decreased from $6.0 \pm 0.4$ to $4.6 \pm 0.3$ in group I, $p<0.05$; and to $3.6 \pm 0.3$ in group $\mathrm{I} / \mathrm{H}, p<0.01$ ). GADD $45 \beta$ expression between groups $\mathrm{I}$ and $\mathrm{I} / \mathrm{H}$ was unchanged $(p>0.05)$. Pre-treatment with SAMe (group $\mathrm{S}-\mathrm{I} / \mathrm{H})$ restored GADD $45 \beta$ expression inhibited by $\mathrm{I} / \mathrm{H}$ (increased to $10.9 \pm 0.8, p<0.01$ ).
A
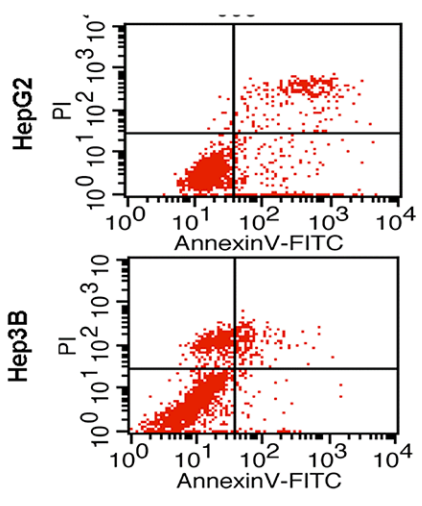

$\mathrm{I} / \mathrm{H}$
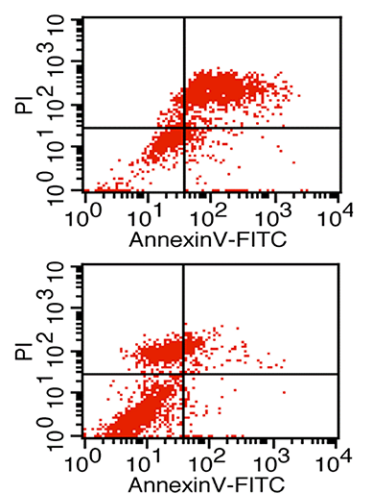

S-I/H
B

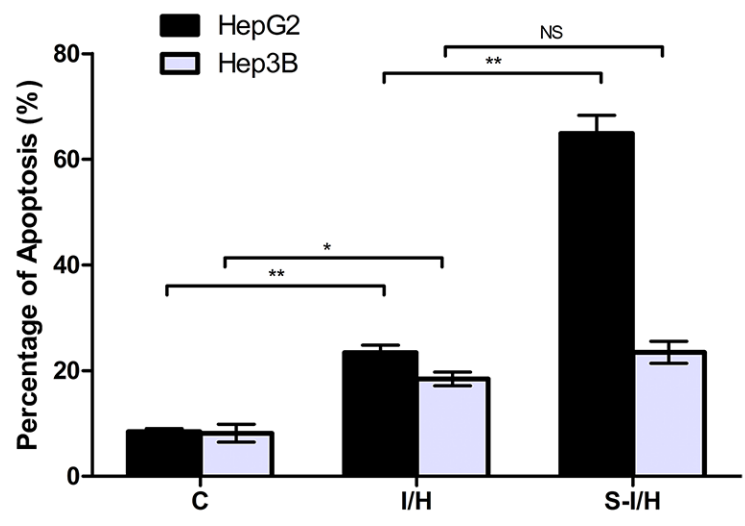

Figure 6: HCC cell apoptosis during acute $\mathbf{I} / \mathbf{H}$, with/without SAMe pre-treatment. HepG2 and Hep3B cell apoptosis was investigated using Annexin V-FITC and PI. $\left(\mathrm{AnV}^{+}\right) \mathrm{PI}^{-}$cells were considered early apoptotic and $\left(\mathrm{AnV}^{+}\right) \mathrm{PI}^{+}$cells were considered late apoptotic and necrotic. NS $p>0.05 ;{ }^{*} p<0.05 ;{ }^{*} p<0.01$. 
Also shown in our previous study [18], SAMe induced GADD $45 \beta$ in Hep3B cells. GADD $45 \beta$ expression increased from $5.3 \pm 0.4$ in controls (group C) to $7.1 \pm 0.6$ in group $\mathrm{S}(p>0.05)$. However, in HepG2 cells, only $\mathrm{I} / \mathrm{H}$ decreased GADD45 $\beta$ expression (to $3.2 \pm 0.3$ ) compared with controls $(p<0.05)$. Moreover, SAMe pre-treatment barely increased GADD45 $\beta$ expression during $\mathrm{I} / \mathrm{H}$ to $5.3 \pm 0.4(\mathrm{~S}-\mathrm{I} / \mathrm{H}$ vs. I/H $p<0.05$, Figure $7 \mathrm{~B})$.

SAMe treatment in HL-7702 cells (Figure 7C) upregulated GADD45 $\beta$; expression increasing to $24.9 \pm 1.2$ in group $\mathrm{S}$ compared with $9.5 \pm 0.6$ in the control group $(p<0.01)$. Ischemia alone (group I) only mildly increased GADD45 $\beta$ levels, to $12.6 \pm 1.1$ compared with $9.5 \pm 0.6$ in the control group $(p>0.05)$. However, $\mathrm{I} / \mathrm{H}$ increased GADD45 $\beta$ levels to $30.1 \pm 1.2$ from control group levels $(p<0.01)$, and pre-treatment with SAMe (group S-I/H) further enhanced GADD45 $\beta$ expression during $\mathrm{I} / \mathrm{H}$. GADD $45 \beta$ expression was $40.7 \pm 3.4$ in group $\mathrm{S}-\mathrm{I} / \mathrm{H}(\mathrm{S}-\mathrm{I} / \mathrm{H}$ vs. I/H, $p<0.05)$.

Further analysis showed that basal GADD $45 \beta$ levels in HepG2 and Hep3B cells were lower compared with HL-7702 cells. GADD45 $\beta$ expression was $6.0 \pm 0.4$, $5.3 \pm 0.4$ and $9.5 \pm 0.6$ in HepG2, Hep3B and HL-7702 cells, respectively. GADD $45 \beta$ expression in the two $\mathrm{HCC}$ cell lines was not statistically different.
As an important downstream regulator of $p 53$, GADD $45 \beta$ status also regulated apoptosis activation on $\mathrm{I} / \mathrm{H}$ treatment. Our results demonstrated that SAMe increased GADD $45 \beta$ expression in Hep3B cells to a greater extend than in HepG2 cells, suggesting that p53 loss might be responsible for the failure of SAMe to induce GADD45 $\beta$ expression. Similar results were observed in terms of apoptosis activation.

Together, our results suggested that during the process of acute $\mathrm{I} / \mathrm{H}$, SAMe increased GADD45 $\beta$ expression and consequently activated apoptosis in $\mathrm{HCC}$ cells to suppress tumor proliferation. p53 status also appeared to influenced apoptotic activity.

\section{DISCUSSION}

Elevated HCC interstitial pressure and high cellular proliferation rates lead to different kinds of $\mathrm{I} / \mathrm{H}$ and reperfusion, which are key components of many pathological conditions [17, 19, 20]. Although transcatheter arterial chemoembolization (TACE) has significantly improved survival in $\mathrm{HCC}$ patients, $\mathrm{I} / \mathrm{H}$ resulting from TACE may allow surviving cancer cells to proliferate and metastasize, resulting in tumor recurrence $[21,22]$. In this study, we confirmed that acute $\mathrm{I} / \mathrm{H}$ could

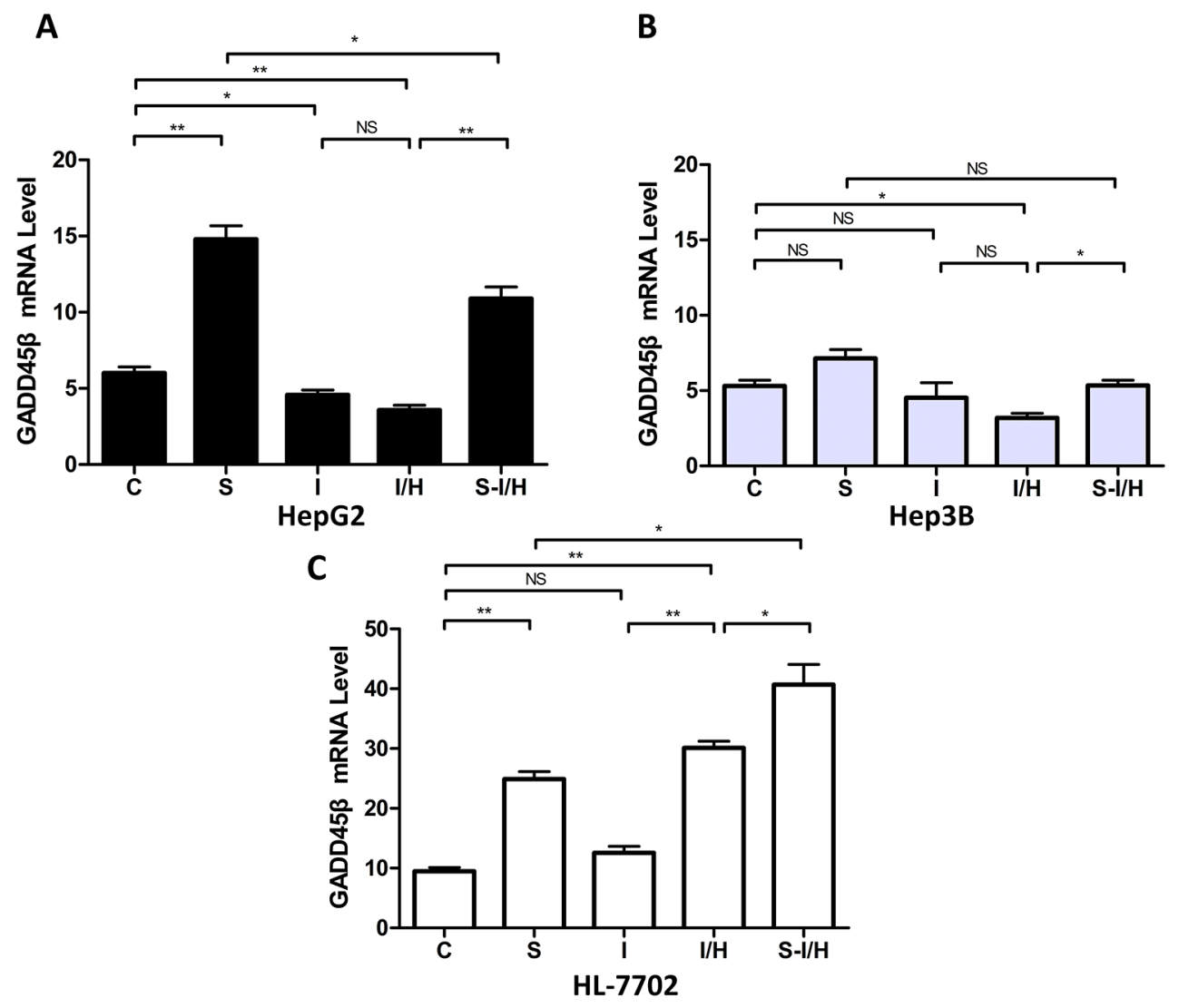

Figure 7: Influence of I/H on GADD45 $\beta$ expression with/without SAMe pre-treatment. (A) GADD45 $\beta$ levels in HepG2 A. Hep3B B. and HL-7702 C. cells in all groups.NS $p>0.05 ;{ }^{*} p<0.05 ; * * p<0.01$. 
enhance proliferation in the HepG2 and Hep3B hepatoma cell lines, and cellular compensation for $\mathrm{I} / \mathrm{H}$ complicated HCC growth, resistance, recurrence and metastasis [23].

Our previous studies showed that SAMe can restore GADD45b expression in HCC and consequently inhibit HCC cell growth, invasiveness and metastasis [24]. In this study, low concentrations of SAMe induced growth of HL-7702 cells, but decreased HepG2 and Hep3B cell viability, which revealed the dual roles of SAMe in HCC cell inhibition and normal liver cell maintenance. Because the response of HCC cells to SAMe treatment during acute $\mathrm{I} / \mathrm{H}$ was largely unknown, the effects of acute $\mathrm{I} / \mathrm{H}$ on cell proliferation with and without SAMe pretreatment were measured. Results showed that HCC cell proliferation resulting from $\mathrm{I} / \mathrm{H}$ was largely inhibited by SAMe pre-treatment. Importantly, inhibition of HCC cell proliferation by SAMe pre-treatment with $\mathrm{I} / \mathrm{H}$ exposure was more apparent than with SAMe treatment alone. The opposite results were observed in normal liver cells.

Metabolic stress, including nutrient deprivation, growth factor deprivation and hypoxia can induce autophagy $[25,26]$. In this study, as evidenced by qualitative and quantitative Beclin 1 detection, we confirmed that autophagy in HCC cells increased on exposure to I/H. Autophagy provides a temporary source of metabolic energy and catabolism intermediates [27] and therefore enables cell survival in nutrient-limited environments [28]. However, the role of autophagy in cancer is still debated [29]. Autophagy may enhance or suppress tumorigenesis. Some autophagy-inducing therapeutic strategies, like Rapamycin, have benefited patients [30]. Similarly, our results illustrated that SAMe, while inhibiting HepG2 and Hep3B cell proliferation, also activated autophagy. Beclin 1 expression increased dramatically in both HepG2 and Hep3B cells with SAMe treatment. HepG2 cell autophagy was further activated with SAMe pre-treatment followed by $\mathrm{I} / \mathrm{H}$ exposure, but this was not observed in Hep3B cells. Autophagy inhibition via ATG7 knockdown inhibited the increase in Beclin 1 expression induced by SAMe, $\mathrm{I} / \mathrm{H}$ treatment, and SAMe pre-treatment in both HepG2 and Hep3B cells. However, ATG7 knockdown had only minor inhibitory effects on $\mathrm{HCC}$ cell proliferation in group $\mathrm{S}-\mathrm{I} / \mathrm{H}$, while proliferation in group $\mathrm{I} / \mathrm{H}$ was largely inhibited. These results indicated that autophagy was not the only mechanism by which SAMe pre-treatment eliminated I/Hinduced cell proliferation. SAMe induced both autophagy and apoptosis, but whether autophagy was an active death-inducing mechanism (cell death by autophagy) or the result of an unsuccessful effort to prolong survival of damaged cells (cell death with autophagy) was difficult to distinguish. Flow cytometry results showed that the percentage of apoptotic $\mathrm{HCC}$ cells exposed to $\mathrm{I} / \mathrm{H}$ alone was much less than in cells pre-treated with SAMe. Therefore, our results suggest that inhibition of HCC cell proliferation via SAMe treatment is accomplished by activating apoptosis.

As a positive apoptosis modulator, GADD $45 \beta$ activation after exposure to genotoxins prevents propagation of damaged cells, causing cell growth arrest and subsequent apoptosis [31]. GADD45 $\beta$ induction could inhibit HCC cell growth and trigger apoptosis via the NF-kB pathway [17]. In this study, SAMe treatment induced GADD $45 \beta$ expression in HCC cells, but I/H exposure only barely did so. Only with SAMe pre-treatment could GADD $45 \beta$ be induced by I/H stimulation. On the contrary, GADD $45 \beta$ expression in normal liver cells was sensitive to both SAMe and $\mathrm{I} / \mathrm{H}$ treatment, and SAMe pre-treatment further activated GADD $45 \beta$ expression already upregulated by $\mathrm{I} / \mathrm{H}$. The blunt response of HCC cells to hypoxia exposure indicated that low GADD45 $\beta$ expression in HCC might lead to a failure to inhibit atypical cell growth or to trigger apoptosis. We hypothesized that autophagy might be responsible for promoting $\mathrm{HCC}$ cell proliferation during $\mathrm{I} / \mathrm{H}$, and induction of GADD $45 \beta$ expression by SAMe pre-treatment was key to inhibiting $\mathrm{HCC}$ cell proliferation under $\mathrm{I} / \mathrm{H}$ conditions via apoptosis.

The GADD45 gene family members are reportedly downstream effectors of $p 53$ required for cell cycle arrest following DNA damage [32], and $p 53$ mutation is closely associated with GADD $45 \beta$ downregulation in HCC. The distinct difference in $p 53$ status between HepG2 (p53-wild type) and Hep3B (p53-null) cells makes them a useful model with which to investigate the role of $p 53$ in SAMe-mediated responses to $\mathrm{I} / \mathrm{H}$. $p 53$-null cells were reportedly insensitive to metabolic stress with a higher intracellular ATP level, but our results demonstrated that autophagy in Hep3B cells was stimulated by $\mathrm{I} / \mathrm{H}$. However, SAMe pre-treatment followed by I/H further activated autophagy in HepG2, but not Hep3B cells, showing that $p 53$ status influenced autophagy activation. Although p53 loss might be responsible for limited SAMe-induced GADD $45 \beta$ expression in Hep3B cells, apoptosis was still partially activated by SAMe pre-treatment followed by I/H. Thus, SAMe-induced proliferation inhibition may be reduced in $p 53$-null cells compared to wild-type cells. Our results related to $p 53$ status confirmed that autophagy may be responsible for promoting cell proliferation during $\mathrm{I} / \mathrm{H}$, and that apoptosis plays a main role in SAMe-induced proliferation inhibition.

In conclusion, GADD $45 \beta$ induction by SAMe enhanced its inhibitory effects on cancer cell proliferation during $\mathrm{I} / \mathrm{H}$ by increasing apoptosis. SAMe protected normal hepatocytes against apoptotic cell death and promoted normal cell regeneration. Consequently, SAMe should be considered a potential therapeutic agent in the management of HCC. 


\section{MATERIALS AND METHODS}

\section{Cell culture, I/H simulation and SAMe treatment}

The human hepatoma cell lines HepG2 and Hep3B were purchased from ATCC, while the established immortalized human fetal hepatic cell line, HL-7702, was purchased from China Center for Type Culture Collection (CCTCC, Wuhan, China) [33]. Cells were cultured as described previously [5].

Acute $\mathrm{I} / \mathrm{H}$ models were established as described previously [9]. Briefly, ischemia was introduced via ischemia mimetic solution (glucose deprivation solution) (pH 6.6, $125 \mathrm{mmol} / \mathrm{L} \mathrm{NaCl}, 8 \mathrm{mmol} / \mathrm{L} \mathrm{KCl}, 1.2 \mathrm{mmol} / \mathrm{L}$ $\mathrm{KH}_{2} \mathrm{PO}_{4}, 1.25 \mathrm{mmol} / \mathrm{L} \mathrm{MgSO}_{4}, 1.2 \mathrm{mmol} / \mathrm{L} \mathrm{CaCl}_{2}$, $6.25 \mathrm{mmol} / \mathrm{L} \mathrm{NaHCO}, 5 \mathrm{mmol} / \mathrm{L}$ Sodium Lactate, and $20 \mathrm{mmol} / \mathrm{L}$ HEPES) [34]. Cells were placed in a hypoxic chamber equilibrated with $95 \% \mathrm{~N}_{2}, 4 \% \mathrm{CO}_{2}$, and $1 \% \mathrm{O}_{2}$ for two hours (ischemia-hypoxia, group $\mathrm{I} / \mathrm{H})$. Glucose deprivation in vitro was utilized to reduce hypoxic response inhibition [35]. Cells treated with ischemia mimetic solution and exposed to normoxia were included as a control for hypoxia (ischemianormoxia, group I). To assess the effect of SAMe on $\mathrm{I} / \mathrm{H}$, cells were pre-treated with $5 \mathrm{mmol} / \mathrm{L}$ SAMe (Knoll Farma- ceutici S.P.A., Milan, Italy) for $24 \mathrm{~h}$ and then I/H was introduced as described above (SAMe-ischemiahypoxia, group $\mathrm{S}-\mathrm{I} / \mathrm{H})$. Cells treated with $5 \mathrm{mmol} / \mathrm{L}$ SAMe for $24 \mathrm{~h}$ acted as negative controls (group S), while cells treated with culture media served as the system control (group C). Two hours after treatment, cells from all groups were harvested at corresponding time points in a parallel manner.

\section{Determination of SAMe dosages and cell proliferation}

HepG2, Hep3B and HL-7702 cells were plated in triplicate at 5,000 cells/well in $100 \mu \mathrm{L}$ media in separate 96-well microtiter plates. The next day, $100 \mu \mathrm{L}$ SAMe was added to the wells at a final dosage of $0,2.5,5.0$, $7.5,10$ or $20 \mathrm{mmol} / \mathrm{L}$ and plates were incubated for an additional 24 hours. Then, $20 \mu \mathrm{L}$ of CCK 8 cellcounting solution (Dojindo Laboratories, Japan) was added to each well and incubated at $37^{\circ} \mathrm{C}$ for 3 hours. Absorbance was read spectrophotometrically at 450 $\mathrm{nm}$ with a reference at $650 \mathrm{~nm}$ using a microtiter plate reader (Tecan Safire 2). Cell viability was calculated according to the following formula: Cell proliferation $(\%)=[(\mathrm{A} 450$ sample-A450blank $) /(\mathrm{A} 450$ controlA450blank)-1]*100. A dose-response curve was constructed to determine the concentration of SAMe that maximally induced HL-7702 proliferation and inhibited HepG2 and Hep3B cell growth.

\section{Beclin 1 and GADD45 $\beta$ mRNA detection by quantitative real-time PCR}

Steady state Beclin 1 and GADD45 $\beta$ mRNA levels were determined by real-time PCR using SYBR Premix Ex Taq (TaKaRa, Japan). After treatment, total RNA was extracted and reversely transcribed to cDNA using Revert Aid First-strand cDNA Synthesis Kit (Fermentas, Canada). GAPDH was used as an endogenous control. Primers pairs were: Beclin 1: 5'-AGC TGC CGT TAT ACT GTT CTG-3' and 5'-ACT GCC TCC TGT GTC TTC AAT CTT-3'; GADD45 $\beta$ : 5'-GGA CCC AGA CAG CGT GGT CCT CTG-3' and 5'-GTG ACC AGG AGA CAA TGC AGG TCT-3'; GAPDH: 5'-GAA GGT GAA GGT CGG AGTC-3' and 5'-GAA GAT GGT GAT GGG ATT TC-3'. Thermal cycling was performed in a 7000 Sequence Detection System (Applied Biosystems). PCR amplification conditions were as follows: $95^{\circ} \mathrm{C}$ for $10 \mathrm{~min}$, 40 cycles of $95^{\circ} \mathrm{C}$ for $15 \mathrm{~s}$, and $60^{\circ} \mathrm{C}$ for $60 \mathrm{~s}$. Ct data was obtained automatically and each data point was performed in triplicate. Relative gene expression was calculated and expressed as $2-\Delta \mathrm{Ct}$.

\section{AVO detection with acridine orange staining}

After treatment, acridine orange (Sigma) was added to culture medium at a final concentration of $1 \mu \mathrm{g} / \mathrm{mL}$ followed by incubation in the dark at room temperature for $15 \mathrm{~min}$. Samples were examined under a fluorescence microscope (Olympics IX71). AVO fluorescence was measured with an excitation wavelength of $488 \mathrm{~nm}$ and an emission wavelength of $515 \mathrm{~nm}$. AVOs were quantitated according to the redto-green fluorescence ratio obtained using Photoshop software (Adobe, San Jose, CA).

\section{Autophagy inhibition by RNA interference}

ATG7 is essential for the autophagy conjugation system, autophagosome formation and starvation-induced degradation of proteins and organelles in mammalian cells [36]. To inhibit autophagy, ATG7 siRNA was transfected into HepG2, Hep3B and HL-7702 cells. The ATG7-targeting sense sequence and the Universal Negative Control siRNA were purchased from Invitrogen (12935-400, Invitrogen, Carlsbad, CA). The human ATG7 sequence (5'-GGAGTCACAGCTCTTCCTT-3') was cloned into Bam 1 and EcoR1 sites of the pGSU6GFP vector (GTP600300, Genlantis, San Diego, CA). siRNA plasmids were transfected using Lipofectamine 2000 (11668019, Invitrogen). Forty-eight hours after transfection, cells were collected by flow cytometry sorting. The irrelevant nucleotides did not targeting any annotated human genes were served as a negative control. 


\section{Apoptosis assay}

HepG2 and Hep3B cell apoptotic status after treatment was evaluated by measuring phosphatidylserine exposure on cell membranes using Annexin V-fluorescein isothiocyanate (Annexin V-FITC) and propidium iodide (PI) staining via the BD Pharmingen Annexin V-FITC Apoptosis Detection Kit I (BD Biosciences). After treatment, cell pellets were centrifuged and washed twice with cold PBS and suspended in $100 \mu \mathrm{l}$ binding buffer. Cells were incubated with $5 \mu 1$ Annexin V-FITC and $5 \mu \mathrm{PI}$ at room temperature for $15 \mathrm{~min}$ in the dark. An additional $400 \mu \mathrm{l}$ of $1 \times$ binding buffer was added to each tube. Samples were analyzed immediately by flow cytometry (Becton Dickinson Facscalibur). 10000 events were acquired using green channel FL1 for Annexin V-FITC and the red channel FL3 for PI. $\left(\mathrm{AnV}^{+}\right) \mathrm{PI}^{-}$ cells were considered early apoptotic, and $\left(\mathrm{AnV}^{+}\right) \mathrm{PI}^{+}$ cells were considered late apoptotic and necrotic. Both subpopulations were counted together and expressed as the total fraction of apoptotic cells.

\section{Statistical analysis}

Statistical analysis was performed using SPSS software (v.13.0). Data was expressed as mean \pm SD of at least three independent experiments. Quantitative data were analyzed using Student's $t$ test between two groups or by one-way ANOVA for multiple groups. A statistically significant difference was defined as $p<0.05$.

\section{CONFLICTS OF INTEREST}

The authors declare no conflicts of interest.

\section{GRANT SUPPORT}

This study was supported by the Nature Science Foundation of China (81172326) and the Shanghai Charity Foundation for Cancer Research.

\section{REFERENCES}

1. Villanueva A, Llovet JM. Targeted therapies for hepatocellular carcinoma. Gastroenterology. 2011; 140:1410-26.

2. Olsen SK, Brown RS, Siegel AB. Hepatocellular carcinoma: review of current treatment with a focus on targeted molecular therapies. Therap Adv Gastroenterol. 2010; 3:55-66.

3. Roberts LR. Sorafenib in liver cancer--just the beginning. N Engl J Med. 2008; 359:420-2.

4. Du H, Yang W, Chen L, Shi M, Seewoo V, Wang J, Lin A, Liu Z, Qiu W. Role of autophagy in resistance to oxaliplatin in hepatocellular carcinoma cells. Oncol Rep. 2012; 27:143-50.

5. Qiu W, David D, Zhou B, Chu PG, Zhang B, Wu M, Xiao J, Han T, Zhu Z, Wang T, Liu X, Lopez R, Frankel P, et al. Down-regulation of growth arrest DNA damageinducible gene 45beta expression is associated with human hepatocellular carcinoma. Am J Pathol. 2003; 162:1961-74.

6. Tian J, Locker J. Gadd45 in the liver: signal transduction and transcriptional mechanisms. Adv Exp Med Biol. 2013; 793:69-80.

7. Das V, Štěpánková J, Hajdúch M, Miller JH. Role of tumor hypoxia in acquisition of resistance to microtubule-stabilizing drugs. Biochim Biophys Acta. 2015; 1855:172-82.

8. Wu CY, Guo XZ, Li HY. Hypoxia and Serum deprivation protected MiaPaCa-2 cells from KAI1-induced proliferation inhibition through autophagy pathway activation in solid tumors. Clin Transl Oncol. 2015; 17:201-8.

9. Du H, Yang W, Chen L, Shen B, Peng C, Li H, Ann DK, Yen Y, Qiu W. Emerging role of autophagy during ischemiahypoxia and reperfusion in hepatocellular carcinoma. Int $\mathrm{J}$ Oncol. 2012; 40:2049-57.

10. Ilisso CP, Sapio L, Delle Cave D, Illiano M, Spina A, Cacciapuoti G, Naviglio S, Porcelli M. S-Adenosylmethionine Affects ERK1/2 and Stat3 Pathways and Induces Apotosis in Osteosarcoma Cells. J Cell Physiol. 2016; 231:428-35.

11. Guo T, Chang L, Xiao Y, Liu Q. S-adenosyl-L-methionine for the treatment of chronic liver disease: a systematic review and meta-analysis. PLoS One. 2015; 10:e0122124.

12. Lu SC, Ramani K, Ou X, Lin M, Yu V, Ko K, Park R, Bottiglieri T, Tsukamoto H, Kanel G, French SW, Mato JM, Moats R, et al. S-adenosylmethionine in the chemoprevention and treatment of hepatocellular carcinoma in a rat model. Hepatology. 2009; 50:462-71.

13. Da MX, Zhang YB, Yao JB, Duan YX. DNA methylation regulates expression of VEGF-C, and S-adenosylmethionine is effective for VEGF-C methylation and for inhibiting cancer growth. Braz J Med Biol Res. 2014; 47:1021-8.

14. Parashar S, Cheishvili D, Arakelian A, Hussain Z, Tanvir I, Khan HA, Szyf M, Rabbani SA. S-adenosylmethionine blocks osteosarcoma cells proliferation and invasion in vitro and tumor metastasis in vivo: therapeutic and diagnostic clinical applications. Cancer Med. 2015; 4:732-44.

15. Bing Y, Zhu S, Yu G, Li T, Liu W, Li C, Wang Y, Qi H, Guo T, Yuan Y, He Y, Liu Z, Liu Q. Glucocorticoid-induced S-adenosylmethionine enhances the interferon signaling pathway by restoring STAT1 protein methylation in hepatitis B virus-infected cells. J Biol Chem. 2014; 289:32639-55.

16. Huang X, Bai HM, Chen L, Li B, Lu YC. Reduced expression of LC3B-II and Beclin 1 in glioblastoma multiforme indicates a down-regulated autophagic capacity that relates to the progression of astrocytic tumors. J Clin Neurosci. 2010; 17:1515-9.

17. Trogadas G, Mastoraki A, Nastos C, Kondi-Pafiti A, Kostopanagiotou G, Smyrniotis V, Arkadopoulos N. Comparative Effects of Ischemic Preconditioning and Iron Chelation in Hepatectomy. J Invest Surg. 2015; 28:261-7.

18. Seewoo V, Yang W, Du H, Wang J, Lin A, Shen B, Peng C, $\mathrm{Li} \mathrm{H}$, Qiu W. The different induction mechanisms of growth 
arrest DNA damage inducible gene $45 \beta$ in human hepatoma cell lines. Chemotherapy. 2012; 58:165-74.

19. Chatterjee N, Das S, Bose D, Banerjee S, Jha T, Saha KD. Leishmanial lipid affords protection against oxidative stress induced hepatic injury by regulating inflammatory mediators and confining apoptosis progress. Toxicol Lett. 2015; 232:499-512.

20. Lencioni R. Loco-regional treatment of hepatocellular carcinoma in the era of molecular targeted therapies. Oncology. 2010; 78 Suppl 1:107-12.

21. Huo YR, Eslick GD. Transcatheter Arterial Chemoembolization Plus Radiotherapy Compared With Chemoembolization Alone for Hepatocellular Carcinoma: A Systematic Review and Meta-analysis. JAMA Oncol. 2015; 1:756-65.

22. Dufour JF, Johnson P. Liver cancer: from molecular pathogenesis to new therapies: summary of the EASL single topic conference. J Hepatol. 2010; 52:296-304.

23. Brahimi-Horn MC, Chiche J, Pouysségur J. Hypoxia and cancer. J Mol Med. 2007; 85:1301-7.

24. Qiu W, Zhou B, Chu PG, Luh F, Yen Y. The induction of growth arrest DNA damage-inducible gene 45 beta in human hepatoma cell lines by S-adenosylmethionine. Am J Pathol. 2007; 171:287-96.

25. Yue Z, Jin S, Yang C, Levine AJ, Heintz N. Beclin 1, an autophagy gene essential for early embryonic development, is a haploinsufficient tumor suppressor. Proc Natl Acad Sci U S A. $2003 ; 100: 15077-82$.

26. Mizushima N, Levine B, Cuervo AM, Klionsky DJ. Autophagy fights disease through cellular self-digestion. Nature. 2008; 451:1069-75.

27. Kolwicz SC Jr, Purohit S, Tian R. Cardiac metabolism and its interactions with contraction, growth, and survival of cardiomyocytes. Circ Res. 2013; 113:603-16.
28. Liu J, Fan L, Wang H, Sun G. Autophagy, a double-edged sword in anti-angiogenesis therapy. Med Oncol. 2016; 33:10.

29. Martinez-Outschoorn UE, Whitaker-Menezes D, Pavlides S, Chiavarina B, Bonuccelli G, Casey T, Tsirigos A, Migneco G, Witkiewicz A, Balliet R, Mercier I, Wang C, Flomenberg $\mathrm{N}$, et al. The autophagic tumor stroma model of cancer or "battery-operated tumor growth": A simple solution to the autophagy paradox. Cell Cycle. 2010; 9:4297-306.

30. Rautou PE, Mansouri A, Lebrec D, Durand F, Valla D, Moreau R. Autophagy in liver diseases. J Hepatol. 2010; 53:1123-34.

31. Liu B, Zhang YH, Jiang Y, Li LL, Chen Q, He GQ, Tan XD, Li CQ. Gadd45b is a novel mediator of neuronal apoptosis in ischemic stroke. Int J Biol Sci. 2015; 11:353-60.

32. Xiao G, Chicas A, Olivier M, Taya Y, Tyagi S, Kramer FR, Bargonetti J. A DNA damage signal is required for p53 to activate gadd45. Cancer Res. 2000; 60:1711-9.

33. Yan YB, Song H, Zhong BS, Wang ZY, Ying SJ, Wang F. Hepatoprotective effect of an immortal human fetal hepatic cell transplantation on CCL(4)-induced acute liver injury in mice. Transplant Proc. 2010; 42:2782-5.

34. Matsui Y, Takagi H, Qu X, Abdellatif M, Sakoda H, Asano T, Levine B, Sadoshima J. Distinct roles of autophagy in the heart during ischemia and reperfusion: roles of AMP-activated protein kinase and Beclin 1 in mediating autophagy. Circ Res. 2007; 100:914-22.

35. Katavetin P, Miyata T, Inagi R, Tanaka T, Sassa R, Ingelfinger JR, Fujita T, Nangaku M: High glucose blunts vascular endothelial growth factor response to hypoxia via the oxidative stress-regulated hypoxia-inducible factor/hypoxia-responsible element pathway. J Am Soc Nephrol 2006; 17:1405-1413.

36. Gonzalez Y, Aryal B, Chehab L, Rao VA. Atg7- and Keap1dependent autophagy protects breast cancer cell lines against mitoquinone-induced oxidative stress. Oncotarget. 2014; 5:1526-37. doi: 10.18632/oncotarget.1715. 